Colloque C2, suppl. au Journal de Physique II, Vo1 1, septembre 1991

\title{
GAS FLOW SIMULATION OF CHEMICAL VAPOUR INFILTRATION IN A VERTICAL HOT-WALL REACTOR
}

\author{
M. SASAKI, A. OHKUBO and T. HIRAI \\ Institute for Materials Research, Tohoku University, \\ Katahira 2-1-1, Sendai 980, Japan
}

\begin{abstract}
Deposition of silicon carbide (SiC) into two types of capillaries $(1.5 \mathrm{~mm}$ dia. $\times 6 \mathrm{~mm}$ depth, 1.0 $\mathrm{mm}$ dia. $\mathrm{x} 4 \mathrm{~mm}$ depth) has been attempted by a vertical hot-wall-type chemical vapour infiltration (CVI) process using an $\mathrm{SiCl}_{4}-\mathrm{CH}_{4}-\mathrm{H}_{2}$ system. Dependence of the deposition temperature (Tdep) and the total gas pressure $\left(\mathrm{P}_{\mathrm{tot}}\right)$ on the thickness distribution of SiC in the two types of the capillaries (parallel and perpendicular to the gas stream) was studied. Activation energy of the deposition of SiC was 42 $\mathrm{kJ} / \mathrm{mol}$ in the Tdep range of 1673 to $1773 \mathrm{~K}$, and $167 \mathrm{~kJ} / \mathrm{mol}$ in the Tdep range of 1573 to $1673 \mathrm{~K}$. The most suitable CVI condition was a Tdep below $1673 \mathrm{~K}$ accompanied by the reaction-rate controlled process. The uniformity of the film thickness obtained atPtotbelow $0.13 \mathrm{kPa}$ was lower than that obtained at Ptot below $13 \mathrm{kPa}$. The lower the Ptot and the closer the deposition was to the capillary entrance, the higher the vorticity in the two types of capillaries became. The film thickness at the capillary entrance increased coincident with the increase in vorticity. Vorticity in the capillaries perpendicular to the gas stream was higher than that parallel to the gas stream. In the diffusion-rate controlled process (Tdep $>1673 \mathrm{~K}$ ), in which decreasing Ptot was accompanied by increasing vorticity, film thickness uniformity in the capillary decreased. Results of the CVI experiments and the gas flow simulation suggest that lower vorticity under reaction-rate controlled conditions is important for obtaining uniformity of $\mathrm{SiC}$ thickness in the capillaries.
\end{abstract}

\section{INTRODUCTION}

Chemical vapour infiltration (CVI) is widely used in the fabrication of fiber-reinforced ceramic composites /1-8/. CVI process can be classified into three main types, an isothermal process /1-4/, a temperature gradient process /5-7/ and a pressure gradient process /8/. Regarding practical applications of ceramic composites, the isothermal CVI process is favourable for manufacturing larger and complex-shaped ceramic composites. Basic research including kinetic study and local gas flow simulation is necessary to extend the applicability of this process.

Use of $\mathrm{C} / \mathrm{C}$ composites is anticipated because of their higher strength ratio and elasticity at high temperatures, although $\mathrm{C} / \mathrm{C}$ composites are not highly oxidation resistant. An oxidation resistant coating on the $\mathrm{C} / \mathrm{C}$ 
composite is indispensable for use in high temperature oxidation atmosphere. Naslain et al. /9/ reported CVI of $\mathrm{SiC}$ into the $\mathrm{C} / \mathrm{C}$ composite using $\mathrm{aCH}_{3} \mathrm{SiCl}_{3}$ (MTS)- $\mathrm{H}_{2}$ system. However, the deposition rate of $\mathrm{SiC}$ is very low (several $\mu \mathrm{mhr}^{-1}$ ). Lackey et al. reported CVI experiments in which the MTS flow rate was $50 \mathrm{~mm}^{3} \mathrm{~min}^{-1}$ and the $\mathrm{H}_{2} / \mathrm{MTS}$ molar ratio was 10 at a $\mathrm{T}_{\text {dep }}$ of $1473 \mathrm{~K}$ and a $\mathrm{P}_{\text {tot }}$ of $100 \mathrm{kPa} / 10 /$. Sugiyama et al. /11/investigated pulse-CVI of SiC into the porous carbon substrate using an $\mathrm{MTS}_{2} \mathrm{H}_{2}$ system at a $\mathrm{T}_{\text {dep }}$ of $1448 \mathrm{~K}$ in which the $\mathrm{P}_{\text {tot }}$ was from 79 to $1.3 \mathrm{kPa}$. Not many research concerning the isothermal CVI of $\mathrm{SiC}$ with gas flows under steady-gas flow conditions has not been attempted.

On the other hand, the present authors have previously reported the influence of the rate-limiting process, a geometrical feature of the CVI hot-zone and the bulk gas flow condition on the CVI process /12/. Local gas flow simulation in the capillaries, however, had not been investigated.

This work describes the importance of local gas flow on the CVI process as shown by CVI experiments and the calculations.

\section{EXPERIMENTAL}

A vertical hot-wall CVI reactor was used for the experiments in an $\mathrm{SiCl}_{4}-\mathrm{CH}_{4}-\mathrm{H}_{2}$ system. A graphite heater (I.D. $40 \mathrm{~mm} \times 75 \mathrm{~mm}$ length) set on the graphite substrate ( $30 \mathrm{~mm}$ dia. $\times 10 \mathrm{~mm}$ length) was heated by the inductive-heating method.

Figure 1 illustrates the CVI hot-zone. The graphite substrate has two types of capillaries ( $1.5 \mathrm{~mm}$ dia. $\mathrm{x} 6$ $\mathrm{mm}$ depth, $1.0 \mathrm{~mm}$ dia. $\times 4 \mathrm{~mm}$ depth) both parallel and perpendicular to the gas stream. CVI experimental conditions are shown in Table $\mathrm{I}$. The $\mathrm{H}_{2}, \mathrm{SiCl}_{4}$ and $\mathrm{CH}_{4}$ gas flow rates were kept constant. Deposition temperature $\left(T_{\text {dep }}\right)$ varied from 1573 to $1773 \mathrm{~K}$, and total gas pressure $\left(P_{\text {tot }}\right)$ varied from 0.13 to $13 \mathrm{kPa}$. SiC thickness was measured by optical microscopy and scanning electron microscopy.

Table I. CVI conditions.

Deposition temperature, $\mathrm{T}_{\text {dep }}(\mathrm{K}) ; 1573$ to 1773
Total gas pressure, $\mathrm{P}_{\text {tot }}(\mathrm{kPa}) ; 0.13$ to 13
Gas flow rate $\left(10^{-6} \mathrm{~m}^{3} \mathrm{sec}^{-1}\right)$
\begin{tabular}{rr}
$\mathrm{SiCl}_{4} ;$ & 1.7 \\
$\mathrm{CH}_{4} ;$ & 1.3 \\
$\mathrm{H}_{2} ;$ & 5.0 \\
Deposition time, $\mathrm{t}_{\text {dep }}(\mathrm{ks}) ;$ & 10.8 \\
\hline
\end{tabular}

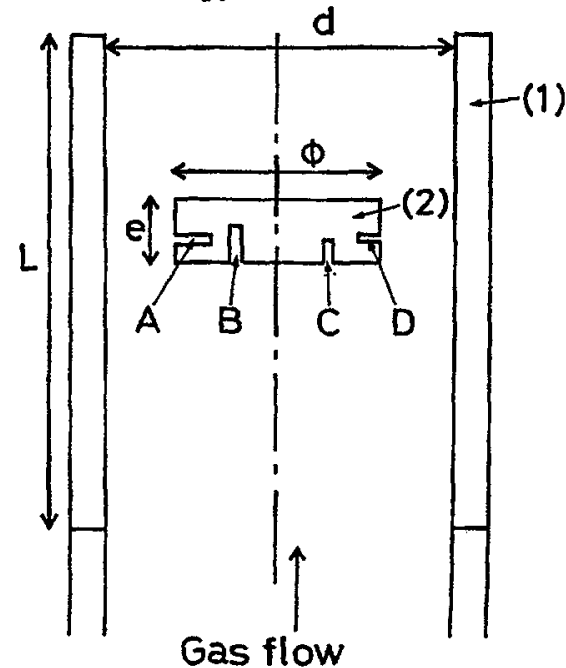

Fig.1.Geometrical diagram of the CVI hot zone, $\mathrm{d}=40 \mathrm{~mm} ; \mathrm{L}=75 \mathrm{~mm} ; \phi=30 \mathrm{~mm} ; \mathrm{e}=10 \mathrm{~mm}$; (1)heater; (2)substrate with 2 types of capillaries: A and $B$, capillary (1.5 $\mathrm{mm}$ dia $\times 6 \mathrm{~mm}$ length); $C$ and $D$, capillary $(1.9 \mathrm{~mm}$ dia $\times 4 \mathrm{~mm}$ length) 


\section{RESULTS AND DISCUSSION}

\subsection{Thickness profiles of the SiC film in the capillaries}

Figures 2 and 3 show that variation in the thickness distribution of SiC in capillaries "A" and "B" was accompanied by variation of the $T_{\text {dep }}$ from 1573 to $1773 \mathrm{~K}$ and variation of the $P_{\text {tot }}$ from 0.13 to $13 \mathrm{kPa}$.

Measurement of the SiC thickness in capillaries "A" and "B" showed that the closer the site of deposition to the capillary entrance, the higher the thickness became at the relatively higher $T_{\text {dep }}(1723-1773 \mathrm{~K})$ under all $\mathrm{P}_{\text {tot }}$ conditions (0.13-13 kPa). The reason for the high level of thickness distribution is thought to be due to the diffusion-rate controlled process at higher $\mathrm{T}_{\mathrm{dep}}$, and $\mathrm{SiC}$ formation is thought to be controlled by the concentration of the source gas. On the other hand, the dependence of the deposition temperature on the thickness distribution is lower in the $T_{\text {dep }}$ range of 1573 to $1723 \mathrm{~K}$, and the dependence of the thickness distribution on $P_{\text {tot }}$ is also higher in this range.

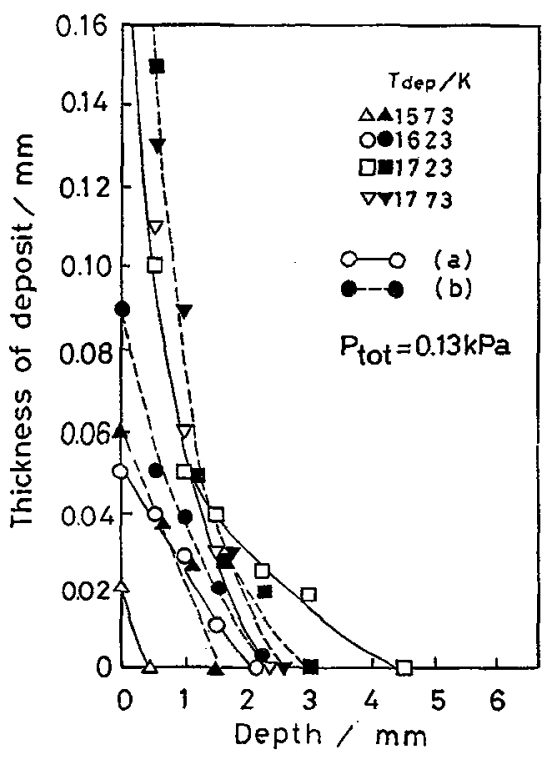

Fig.2.Thickness distribution of $\mathrm{SiC}$ in the capillaries A (a) and B (b).

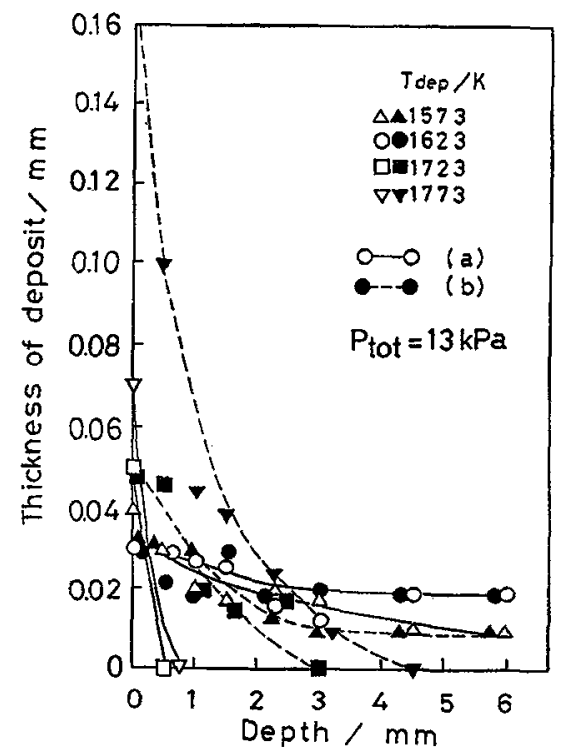

Fig.3.Thickness distribution of $\mathrm{SiC}$ in the capillaries $A(a)$ and $B(b)$.

Figures 4 and 5 show the effect of $P_{\text {tot }}$ on the thickness distribution in capillaries " $A$ " and " $B$ " at $T_{\text {dep }}$ of 1773 and $1623 \mathrm{~K}$. Figure 4 demonstrates the independence of the thickness distribution on $P_{\text {tot }}$ at a $T_{\text {dep }}$ of $1773 \mathrm{~K}$. This result shows that a $\mathrm{T}_{\text {dep }}$ of $1773 \mathrm{~K}$ is not suitable for CVI conditions. In this case, CVI parallel to the gas stream is better than CVI perpendicular to the gas stream. Figure 5 shows the effect of $\mathrm{P}_{\text {tot }}$ on $\mathrm{SiC}$ thickness distribution in capillaries " $A$ " and " $B$ " under reaction-rate controlled conditions $\left(T_{\text {dep }}=1623 \mathrm{~K}\right)$. The 
uniformity of the thickness is high at a $\mathrm{T}_{\mathrm{dep}}$ of $1623 \mathrm{~K}$ and a $\mathrm{P}_{\text {tot }}$ of $13 \mathrm{kPa}$. This tendency is thought to be due to the reaction-rate controlled process. $\mathrm{A} \mathrm{T}_{\text {dep }}$ of $1623 \mathrm{~K}$ and a $\mathrm{P}$ tot of $0.13 \mathrm{kPa}$ are not good conditions for $\mathrm{CVI}$ in contrast with the same $\mathrm{T}_{\text {dep }}$ and $\mathrm{a} \mathrm{P}_{\text {tot }}$ of $13 \mathrm{kPa}$ as mentioned above.

Gas flow simulation was attempted under viscous flow conditions. Calculated temperature distribution in the CVI hot-zone at the $\mathrm{P}_{\text {tot }}$ of $13 \mathrm{kPa}$ is shown in Fig. 6. Temperature uniformity around the substrate within $10 \mathrm{~mm}$ was very high. This result shows that this CVI experiment was conducted under isothermal conditions.
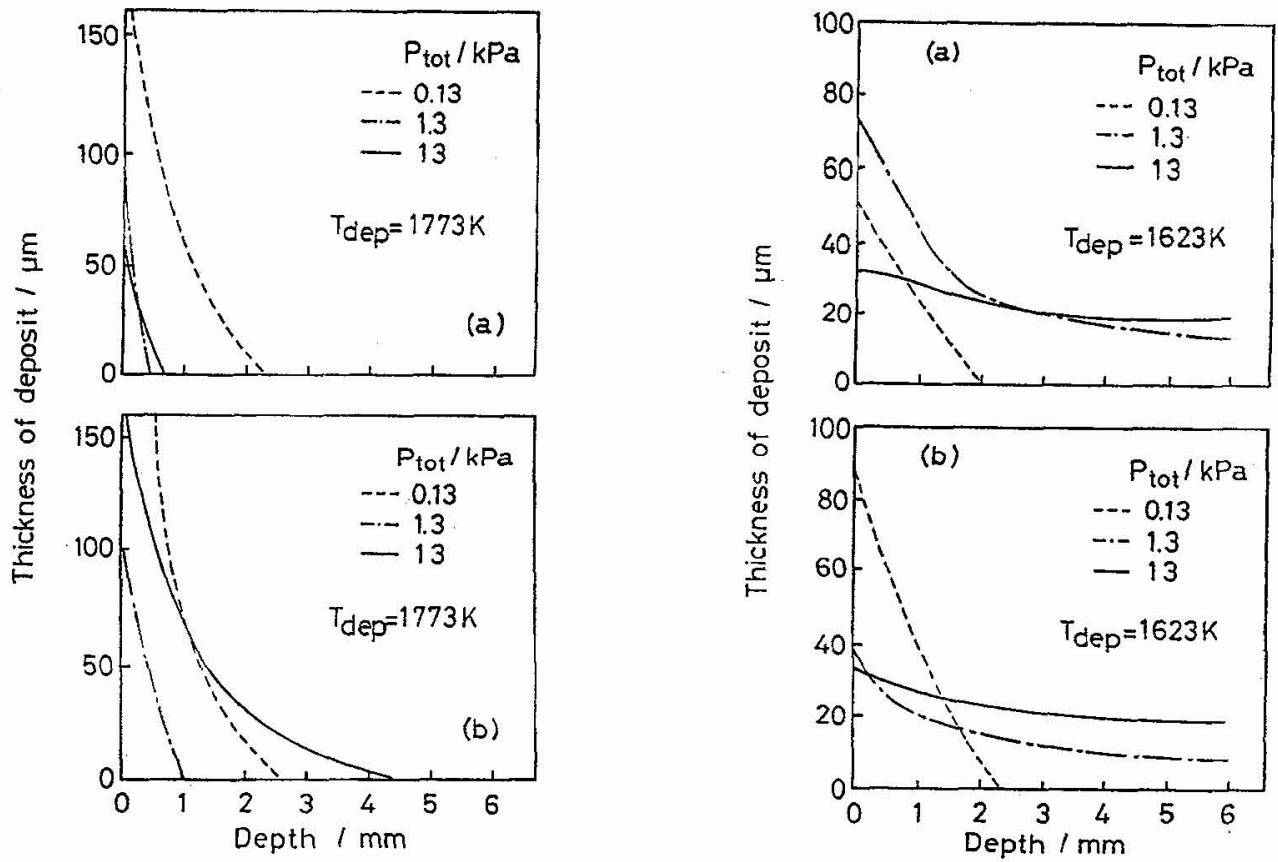

Fig.4.Effect of total gas pressure $\left(\mathrm{P}_{\text {tot }}\right)$ on the SiC Fig.5.Effect of total gas pressure $\left(\mathrm{P}_{\text {tot }}\right)$ on the SiC thickness distribution in the capillaries A (a) and B thickness distribution in the capillaries A (a) and B (b).

(b).
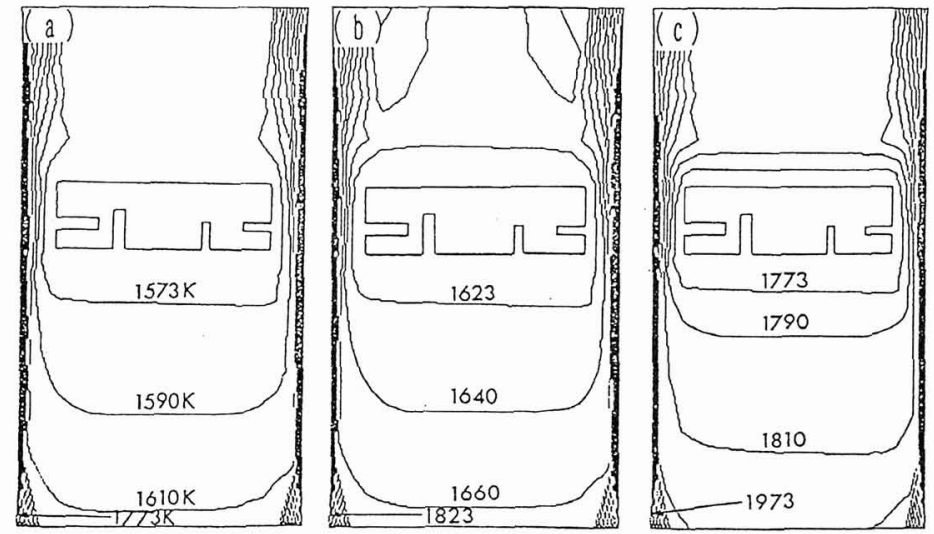

Fig.6.Temperature profile in the CVI hot zone at $\mathrm{P}_{\mathrm{rot}}=13 \mathrm{kPa}\left(\mathrm{T}_{\text {dep }}=(\mathrm{a}) 1573 \mathrm{~K}\right.$; (b) $1623 \mathrm{~K}$; (c) 1773 K). 
3.2. Dependence of total gas pressure on the flow rate and vorticity

Figure 7 shows the calculated stream lines in the CVI hot-zone at a $\mathrm{T}_{\text {dep }}$ of $1573 \mathrm{~K}$. With a decrease in the $\mathrm{P}_{\text {tot }}$, the distance between stream lines became narrower and the flow rate and the flow rate distribution increased with decreasing $\mathrm{P}_{\text {tot }}$ as shown by calculation of the flow rate distribution using the stream function. This calculated result shows the flow rate distribution around the substrate and the heater.
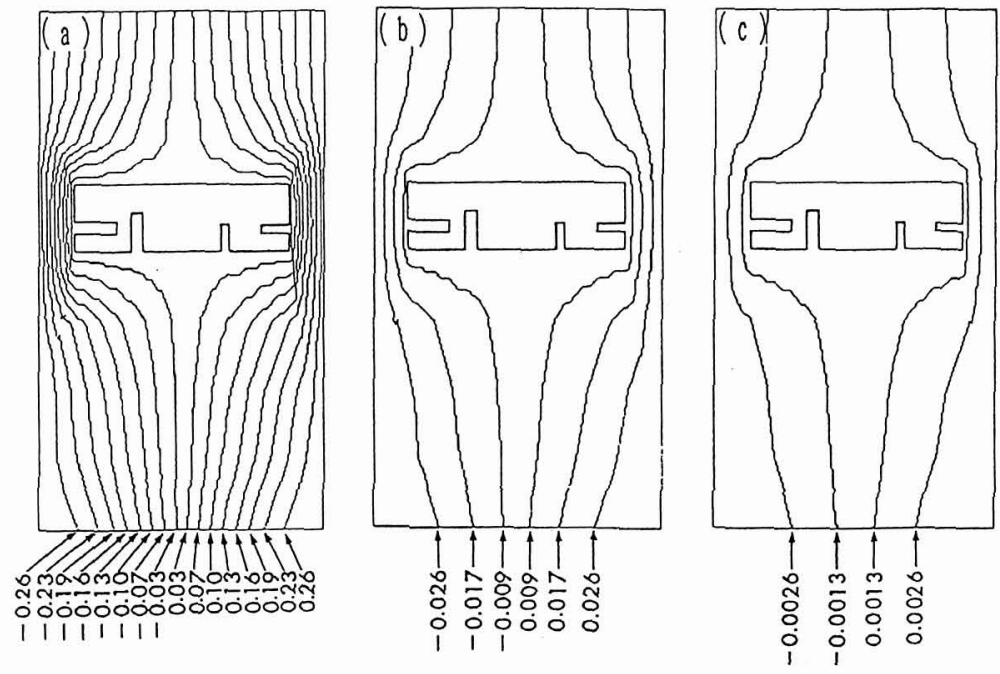

Fig.7.Stream line in the CVI hot zone at $\mathrm{T}_{\mathrm{dep}}=1573$ $\mathrm{K}\left(\mathrm{m}^{2} \mathrm{sec}^{-1} ; \mathrm{P}_{\text {tot }} ;(\mathrm{a}) 0.13 \mathrm{kPa}\right.$; (b) $1.3 \mathrm{kPa}$; (c) $13 \mathrm{kPa}$ ).

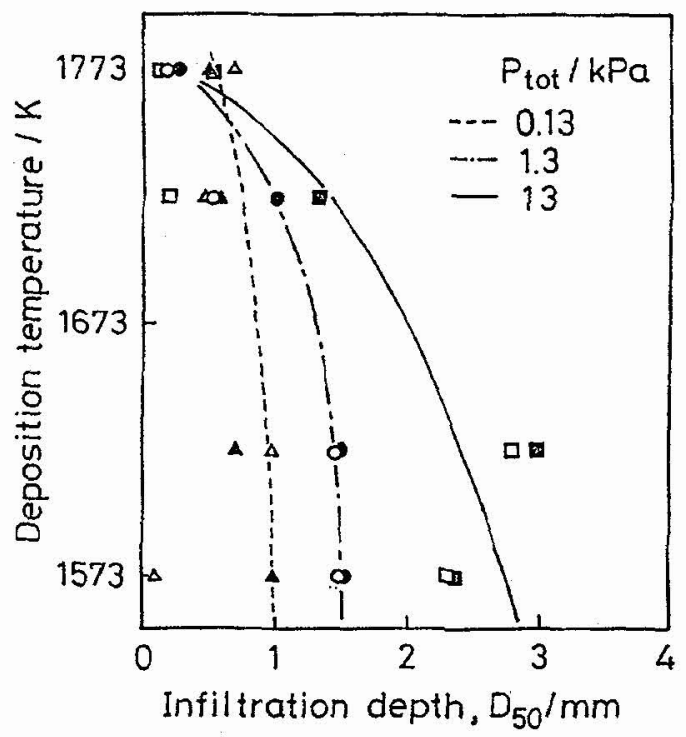

Fig.8.Dependence of the infiltration depth on $\mathrm{T}_{\text {dep }}$ and $\mathrm{P}_{\text {tot }}(\triangle 0.13 \mathrm{kPa} ; 01.3 \mathrm{kPa} ; \square 13 \mathrm{kPa})$ open circle:perpendicular to the gas stream, closed circle:parallel to the gas stream. 
Figure 8 demonstrates the dependence of the infiltration depth on $\mathrm{T}_{\text {dep }}$ and $\mathrm{P}_{\text {tot }}$. The infiltration depth (D50) is defined as the place in which the thickness fell to a level fifty percent lower than that at the entrance. These results show that the conditions at lower $\mathrm{T}_{\text {dep }}(<1623 \mathrm{~K})$ and higher $\mathrm{P}_{\text {tot }}(>=13 \mathrm{kPa})$ are suitable for CVI.

\subsection{Relationship between vorticity and infiltration depth}

Generally "vorticity" defines as a degree of self-rotating velocity in a local flow accompanied with a distribution of gas flow velocity. Figure 9 shows the calculated vorticity in the capillaries at $\mathrm{T}_{\text {dep }}$ of $1573 \mathrm{~K}$. The ratios of the capillary depth to diameters of about $1.0 \mathrm{~mm}$ and $1.5 \mathrm{~mm}$ (conversion depth) for diameters of about $1.0 \mathrm{~mm}$ and $1.5 \mathrm{~mm}$ agree well with each other. These results are supported by our previous experiments 112/. Vorticity increases with decreasing $\mathrm{P}_{\text {tot }}$ and decreasing depth from the capillary entrance as shown in Fig. 9. Figure 10 demonstrates the relationship between the vorticity and the infiltration depth. Vorticity becomes lower at a $\mathrm{P}_{\text {tot }}$ of $13 \mathrm{kPa}$ in the $\mathrm{T}_{\text {dep }}$ range of 1573 to $1773 \mathrm{~K}$. Vorticity in a capillary entrance increased with decreasing $\mathrm{P}_{\text {tot }}$. Source gas diffusion makes difficult under relatively high $\mathrm{P}_{\text {tot: }}$. These calculated results suggest that the lower vorticity resulting from higher $P_{\text {tot }}$ and the lower $T_{\text {dep }}$ due to the reaction-rate controlled condition are important in CVI processing.

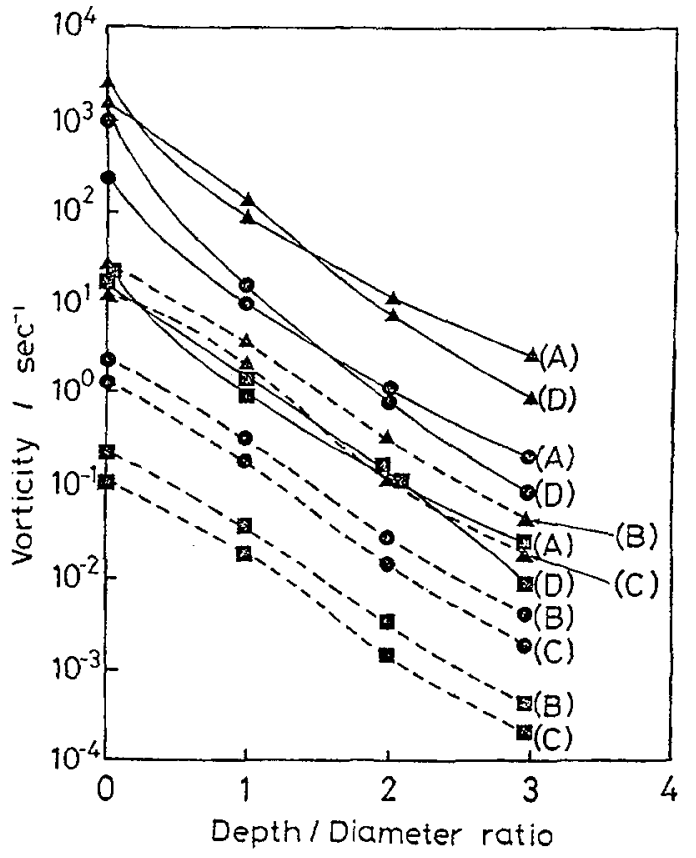

Fig.9. Vorticity in the capillary at $\mathrm{T}_{\mathrm{dep}}=1573 \mathrm{~K}$ :(A) and $(D)$ perpendicular to the gas stream; $(B)$ and $(C)$ parallel to the gas stream; $(A)$ and $(B)$ are $1.5 \mathrm{~mm}$ diameter, $(C)$ and $(D)$ are $1.0 \mathrm{~mm}$ diameter $\left(P_{\text {tot }}\right.$ : $0.13 \mathrm{kPa} ; 1.3 \mathrm{kPa} ; 13 \mathrm{kPa}$ ).

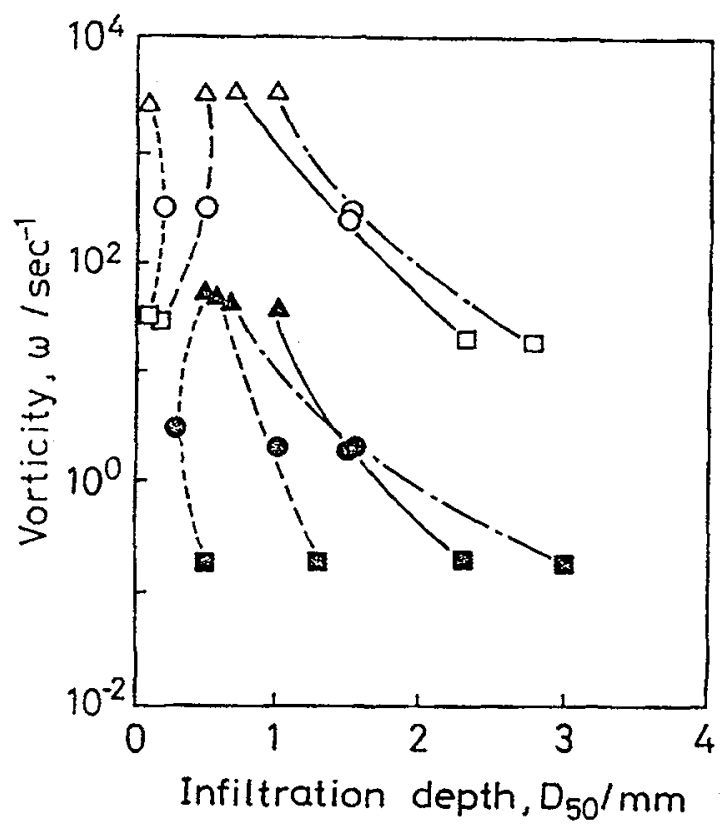

Fig.10.Dependence of the infiltration depth on the vorticity $\left(\mathrm{T}_{\text {dep }}:(-) 1573 \mathrm{~K} ;(-\rightarrow 1623 \mathrm{~K} ;(-\rightarrow 1723 \mathrm{~K}\right.$; (…) $\left.1773 \mathrm{~K}, \mathrm{P}_{\text {tot }}:(\Delta, \Delta) 0.13 \mathrm{kPa} ;(0, \bullet) 1.3 \mathrm{kPa} ; \square, \square\right) 13$ $\mathrm{kPa}$, open circle:perpendicular to the gas stream, closed circle:parallel to the gas stream). 


\section{CONCLUSIONS}

CVI experiments on deposition of $\mathrm{SiC}$ into capillaries perpendicular to the gas stream (capillaries " $\mathrm{A}$ " and "D") and parallel to the gas stream (capillaries " $\mathrm{B}$ " and " $\mathrm{C}$ "), and related gas flow simulation yielded the following conclusions:

(1) The rate-limiting process is thought to be due to diffusion-control at $T_{\text {dep }}$ of 1673 to $1773 \mathrm{~K}$ and to reactioncontrolled at $T_{\text {dep }}$ of 1573 to $1673 \mathrm{~K}$ in the whole $P_{\text {tot }}$ range of 0.13 to $13 \mathrm{kPa}$.

(2) CVI into capillary " $B$ " parallel to the gas stream is easier than CVI into capillary " $A$ " perpendicular to the gas stream.

(3) The thickness uniformity increased with increasing $\mathrm{P}_{\text {tot }}$ from 0.13 to $13 \mathrm{kPa}$ at a lower $\mathrm{T}_{\text {dep }}$ of $1623 \mathrm{~K}$.

(4) Suitable CVI conditions for SiC deposition into the capillaries both parallel and perpendicular to the gas stream are lower $T_{\text {dep }}(<1623 \mathrm{~K})$ and higher $P_{\text {tot }}(>=13 \mathrm{kPa})$.

(5) Flow rate distribution and vorticity increased with decreasing $P_{\text {tot }}$ and the distance from the capillary entrance.

\section{REFERENCES}

/1/MORIN D., J. Less-Common Met., 47(1976)207.

/2/NEWKIRKL.R., RILEY R.E., SHIEINBERGH., VALENCIA F.A. and WALLACE T.C., Proc. 7 th Conf. Chemical Vapor Deposition,eds. T.O. Sedgwick and H. Lydtin (Electrochem. Soc., Pennington, 1979), p.515. 13/HERAUDL.H., CHRISTIN F., NASLAIN R. and HAGENMULLER P., Proc. 8th Conf. Chemical Vapor Deposition, eds. J.M. Blocher,Jr. and G.E. Vuillard (Electrochem. Soc., Pennington, 1981), p.782.

14/ FITZER E., HEGEN D. and STROHMEIER H., Proc. 7th Conf. Chemical Vapor Deposition, eds. T.O. Sedgwick and H. Lydtin (Electrochem. Soc., Pennington, 1979), p.525.

15/ CAPUTO A.J. and LACKEY W.J., Ceram. Eng. Sci. Proc., 5(1984)654.

/6/ THEIS Jr. J.D., Proc. 3th Conf. Cemical Vapor Deposition, eds. F.A. Glaski (Electrochem. Soc., Pennington, 1972), p.561.

7// GEBHARDT J.J., Proc. 4th Conf. Chemical Vapor Deposition, eds. G.F. Wakefield and J.M. Blocher (Electrochem. Soc., Pennington, 1973), p.460.

/8/ SUGIYAMA K. and NAKAMURA T., J. Mat. Sci. Lett., 6(1987) 331.

19/ HERAUD L.H., CHRISTINF., NASLAIN R. and HAGENMULLER P., Proc. 8th Conf. Chemical Vapor Deposition, eds. J.M. Blocher,Jr. and G.E. Vuillard (Electrochem. Soc., Pennington, 1981), p.782. /10/CAPUTO A.J. and LACKEY W.J., Ceram. Eng. Sci. Proc., 5(1984)654.

/11/SUGIYAMA K. and YAMAMOTO E., Proc. 10th Conf. Chemical Vapor Deposition, eds. G.W. Cullen and J.M. Blocher, Jr. (Electrochem. Soc., Pennington, 1987), p.1041.

/12/SASAKI M., OHKUBO A., SUZUKI T. and HIRAI T., J. Mat. Res., submitted. 